60-61| 2018

La culture dans l'enseignement du français langue étrangère: conceptions théoriques, programmes et manuels auX $\mathrm{XIX}^{\mathrm{e}}$ et $\mathrm{XX}^{\mathrm{e}}$ siècles

\title{
Préface
}

\section{Despina Provata}

\section{(2) OpenEdition \\ Journals}

Édition électronique

URL : https://journals.openedition.org/dhfles/4543

DOI : $10.4000 /$ dhfles. 4543

ISSN : 2221-4038

\section{Éditeur}

Société Internationale pour l'Histoire du Français Langue Étrangère ou Seconde

Édition imprimée

Date de publication : 1 janvier 2018

ISSN : 0992-7654

\section{Référence électronique}

Despina Provata, «Préface », Documents pour l'histoire du français langue étrangère ou seconde [En ligne], 60-61 | 2018, mis en ligne le 02 juillet 2019, consulté le 03 avril 2023. URL : http:// journals.openedition.org/dhfles/4543; DOI : https://doi.org/10.4000/dhfles.4543

Ce document a été généré automatiquement le 3 avril 2023.

Tous droits réservés 


\section{Préface}

\section{Despina Provata}

1 Aujourd'hui il est plus qu'évident que l'apprentissage d'une langue étrangère implique une compétence culturelle et on ne saurait dissocier la culture de la langue ni de son enseignement. Mais il n'en a pas toujours été ainsi.

2 En effet, en fonction du mouvement de l'histoire on a pu observer différentes conceptions de la culture. Si les indices d'un certain intérêt pour les particularités françaises sont présents dans les supports pédagogiques relativement tôt, dès le XVI ${ }^{\mathrm{e}}$ siècle, c'est surtout à partir du XVIII ${ }^{\mathrm{e}}$ siècle que la langue française se voit investie d'une mission civilisatrice. Les Belles Lettres occupent dès lors un rôle central dans l'enseignement. Présents dans les manuels et les chrestomathies les textes littéraires, sous forme d'extraits, servaient alors à la traduction, à la pratique des règles grammaticales ou au perfectionnement de la prononciation.

3 Ainsi, au moment où s'affirme la supériorité culturelle de la France et que le français s'impose au XIX ${ }^{\mathrm{e}}$ siècle à travers l'Europe comme langue des élites, la formation littéraire, considérée comme l'essence même de la culture française, devient l'un des objectifs de la discipline naissante du FLE. Sous l'influence du modèle des humanités classiques adopté dans les pays européens, connaître la langue de l'Autre était avant tout connaître les monuments de sa littérature. Cette approche de la culture pénètre tous les aspects de l'enseignement: elle définit les approches méthodologiques, elle oriente les programmes scolaires, elle est enfin liée à la formation même des enseignants et à leurs choix dans l'enseignement du français.

4 À la fin du XIX siècle et dans les premières décennies du $\mathrm{XX}^{\mathrm{e}}$ siècle s'amorce un tournant décisif dans l'histoire de l'enseignement des langues. Sous l'influence de la méthode directe, qui accorde la priorité à la langue orale, sont introduits dans le cours de français les images, les objets, les gestes voire la mimique. La culture n'est plus attachée exclusivement à la littérature et aux arts, elle s'élargit pour contenir la culture quotidienne, les réalités historiques et la géographie. L'enseignement traditionnel est alors abandonné et le texte littéraire est mis de côté au profit du texte non-littéraire. On s'intéresse aussi bien aux produits spirituels qu'à la création matérielle d'un pays sans oublier ce qui définit les caractéristiques d'un peuple, à savoir la mentalité. 
Si dans les années 1950 la méthode audio-orale, qui se développe sous l'emprise de la linguistique structurale et du behaviorisme, échoue, elle contribue cependant à un certain élargissement du concept de la culture. En mettant l'accent sur les différences dans les façons de vivre, elle favorise le projet d'un comparatisme culturel. Mais on est encore loin de l'approche interculturelle introduite par l'approche communicative au $\mathrm{XX}^{\mathrm{e}}$ siècle.

6 En effet, dans les années 1980, et grâce au développement de l'anthropologie et de l'ethnologie, l'enseignement de la civilisation étrangère devient un élément indispensable de l'enseignement des langues étrangères. Pour Galisson (1986) la langue et sa culture deviennent alors indissociables et il affirme, par un trait-d'union significatif, l'égalité entre ces deux éléments, langue-culture.

7 Ce sont enfin, les modifications et les évolutions au sein de l'Europe des années 1990, qui conduisent à une nouvelle conception du fait culturel. Devant la création d'un espace européen unifié, la nécessité d'une prise de conscience interculturelle se fait davantage sentir. L'apprenant est dorénavant considéré comme un acteur social ayant à accomplir aussi des tâches extra-langagières.

8 Plusieurs études publiées dans la revue Documents s'étaient penchées sur le poids de la culture dans l'enseignement $d u$ français langue étrangère. On peut citer certains points d'intérêt au risque d'en oublier beaucoup d'autres: le comparatisme culturel en Hollande (Kok Escalle \& Van Strien-Chardonneau 2005) la notion de «langue de civilisation» (Suso López \& Fernández Fraile 2008), l'enseignement de la culture française en Italie (Minerva 2010), la culture française dans un manuel destiné à l'éducation du Prince en Perse (Kok Escalle 2012), la culture française dans l'enseignement du FLE en Serbie (Stikić 2015), les images de la culture française dans la presse périodique néerlandaise du XIX ${ }^{\mathrm{e}}$ siècle (Koffeman 2014)... Mais une série de questions restaient encore à débattre.

9 À partir de quel moment la culture et la civilisation ont commencé à faire partie du champ de la didactique du français langue étrangère? Comment se définissent les rapports entre les savoirs culturels et les savoirs langagiers? Comment s'expriment les différentes manières de concevoir la langue et la culture au fil du temps dans le cadre des méthodologies de l'enseignement du français langue étrangère ou seconde ? Peuton définir les étapes de ce phénomène et en relever des ressemblances et/ou influences entre les différents pays européens? Quel fut le rôle des institutions, officielles ou officieuses dans la définition du fait culturel ? Quel fut - enfin - le rôle des enseignants et/ou des auteurs de manuels en tant que médiateurs entre deux langues et deux cultures?

10 Pour apporter des réponses à ces questions, la SIHFLES a, en collaboration avec le Département de Langue et Littérature françaises de l'Université nationale et capodistrienne d'Athènes, organisé un colloque international «La culture dans l'enseignement du français langue étrangère : conceptions théoriques, programmes et manuels (XIX ${ }^{\mathrm{e}}$-XX ${ }^{\mathrm{e}}$ siècles)». Le colloque s'est tenu à Athènes du 11 au 13 mai 2017. Le présent volume rassemble une série d'études sélectionnées pour publication issues de cette rencontre dans le but de présenter la problématique et les aboutissements de ces journées.

11 Afin de cerner les différentes conceptions de la culture et de définir la perception que l'on se fait de l'autre, Marcus Reinfreid nous invite à emprunter une approche 
diachronique et examiner le paradigme allemand. Avec comme point de départ le XIX ${ }^{\mathrm{e}}$ siècle, lorsque sous l'influence du néo-humanisme la littérature française prend sa place dans les lycées allemands, classiques et modernes, l'auteur montre comment au lendemain du mouvement de la réforme allemande, l'enseignement des realia privilégie le texte non-littéraire et place sur un pied d'égalité la culture française et la culture locale. La volonté d'analyser le caractère français recule sous la perspective nationaliste de la Kulturkunde qui accorde la primauté à la reconnaissance approfondie du caractère allemand, avant que la méthode communicative n'établisse l'enseignement de la civilisation quotidienne qui mènera au recul du concept de la compréhension de l'autre au profit d'une approche transculturelle dans l'enseignement des langues, dans les années 1990.

12 Le panorama historique interprétatif de l'évolution des idées des didactologues, que proposent Véronique Castellotti et Marc Debono, élargit l'approche théorique de la notion de civilisation/culture. Suivre l'évolution de la conceptualisation didactique de l'enseignement culturel, à partir de la contestation de l'approche civilisationnelle, accusée d'incarner des conceptions coloniales et élitistes, vers une orientation plus pragmatique, invite à une réflexion portant sur le renouvellement de la notion de culture et d'interculturel.

13 Ré-actualiser le rôle de la littérature, comme le suggèrent Castellotti et Debono, implique aussi une volonté de chercher dans le passé de l'enseignement du français et des pratiques adoptées au fil du temps. Javier Suso Lopez remonte au XVIII ${ }^{\mathrm{e}}$ siècle, lorsque l'utilité pratique et professionnelle de la langue est couplée d'une composante culturelle. Initialement d'ordre ethnologique, le culturel est par la suite associé au littéraire. La formation "littéraire » constitue alors l'un des objectifs de la discipline naissante du FLE et les maîtres de langue, passeurs de culture, sont invités à initier leurs élèves à un français, non plus langue utilitaire, mais langue de distinction et outil de formation intellectuelle.

14 Adoptant une approche comparatiste, Alicia Piquer Desvaux montre d'une part comment cette pratique donne naissance en Espagne à des anthologies de littérature française spécialement conçues pour les besoins éducatifs, telle celle de Francisco Tramarría et d'autre part, comment l'hégémonie culturelle française est contestée à travers la grammaire allemande de Carlos Fernández de Castroverde. Face à l'anthologie de Tramarría qui propose des textes choisis pour leur valeur morale et pour préparer les futurs étudiants au bon usage de la langue française, Castroverde déplore la dépendance de la culture espagnole à l'égard de la culture de la langue française et propose le modèle culturel allemand.

C'est par rapport aux célèbres Leçons françaises de littérature et de morale de François Noël et François de la Place, qui ont largement circulé en Europe au cours du XIX ${ }^{e}$ siècle, que Maria Eugenia Fernandez Fraile examine trois recueils de textes publiés en Espagne dans la première moitié du siècle. L'auteur montre comment, à travers ces chrestomathies mais aussi à travers d'autres recueils de morceaux choisis, les maitres espagnols ont pu satisfaire le triple but que s'assignait l'enseignement du français : la formation culturelle, littéraire et linguistique des apprenants, susceptible de leur permettre de se projeter non pas dans la culture nationale mais dans la culture française voire dans la culture classique.

16 Cependant, dans le cas espagnol, cette approche de la culture française reste en grande partie sélective, comme l'explique dans son article Juan Francisco García Bascuñana, 
car tout au long du XIXe, la littérature du Moyen Âge fait défaut dans les manuels de français. Si ce phénomène s'estompe au lendemain de Première Guerre mondiale, c'est d'une part redevable aux choix de la nouvelle génération de professeurs formées dans les romanités mais aussi à cause de l'usage idéologique que fait le régime franquiste du Moyen Âge qui y trouve autant d'arguments pour soutenir ses objectifs moraux et patriotiques.

Dans les années 1960, cette conception de la culture savante est remise en question sous l'influence de la sociologie. Evelyne Argaud porte son attention sur l'évolution du concept de civilisation/culture dans les pages de la revue pédagogique Le Français dans le monde où se déploie un débat qui oppose conservateurs et progressistes, tradition et modernité. Cette rupture avec la tradition et l'enseignement de la civilisation a, finalement, apporté une meilleure connaissance des réalités françaises.

La diffusion du français implique aussi une certaine approche idéologique de la culture et du rôle de la diplomatie d'influence, facteur déterminant dans les rapports entre la France et les différents pays. Le rôle des institutions dans la mise en place d'une véritable politique culturelle et linguistique ainsi que leur apport dans la disciplinarisation du champ culturel dans les systèmes éducatifs des différents pays, s'avère central dans le cadre d'initiatives qui se déploient à l'étranger ou pour des étrangers.

Fondée pour promouvoir le français à travers le monde, l'Alliance française inaugure en 1894 des Cours de vacances destinés aux professeurs étrangers. Claude Cortier examine l'organisation et les contenus de ces cours qui allient le français pratique et des cours de civilisation sur la France contemporaine, le tout complété par des visites culturelles et des conférences. Avec des effectifs toujours grandissants et un succès certain, l'Alliance française demeure fidèle à la tradition littéraire et à celle d'une culture-civilisation. L'auteur critique, cependant, la sectorisation qui conduit à séparer la langue et la culture au sein du même établissement.

Dans le secteur de la diffusion et de l'enseignement du français langue seconde dans les colonies françaises, Gérard Vigner exploite la nouvelle pédagogie du langage spécialement conçue à l'intention de l'école coloniale. Si cet enseignement privilégie la leçon de choses et le français oral, l'objectif étant de mettre les élèves en contact avec une langue simple, libérée de tout souci stylistique et d'élaboration littéraire, il est toutefois doublé d'un objectif idéologique qui vise à offrir une représentation du monde conforme à l'univers des élèves « indigènes » afin de les persuader de la légitimité de la présence française sur leur territoire et de celle de ses initiatives " civilisatrices ».

21 Spécialement conçus pour des élèves allophones, les livres de lecture publiés entre 1885 et 1930 qui retiennent l'attention de Valérie Spaëth permettent de saisir la complexité de la relation entre langue, culture et civilisation. Initialement destinés à l'apprentissage du français, qui n'est pas la langue maternelle des élèves, ils obéissent à des objectifs variés qui s'inscrivent aussi bien dans le projet de la $\mathrm{III}^{\mathrm{e}}$ République d'enracinement de la langue et de la culture en territoire national que dans les enjeux de la propagande coloniale.

C'est dans un contexte différent, celui la Palestine, où les Français ne sont pas des colonisateurs officiels mais où la langue française est enseignée depuis le XIX ${ }^{e}$ siècle, que Clémentine Rubio examine la représentation de la culture et sa relation avec la langue. Les documents diplomatiques de nature diverse (courrier et circulaires, coupures de presse et photos) permettent de saisir la complexité de la relation langue, 
culture et mentalité mais aussi deux conception différentes de la civilisation: l'une visant à un processus susceptible de permettre l'élévation des populations et l'autre indiquant un niveau de civilisation à atteindre, conforme à l'image que se faisaient les diplomates et leurs interlocuteurs et qui n'est pas dénuée de rapports de domination.

Ce sont également les relations diplomatiques entre la France et la Grèce qui influencent les contenus culturels du programme de formation des francisants en Grèce, comme le démontre Loukia Efthymiou. Si la collaboration franco-hellénique qui se met en place au début $\mathrm{du} \mathrm{XX}^{\mathrm{e}}$ siècle contribue à la mise en place d'une structure initiale visant à former les futurs enseignants, les conflits entre les deux partenaires n'ont pas manqué, ce qui se répercute dans les orientations des programmes du département d'études françaises de l'université d'Athènes, fondé en 1954.

Plusieurs études de cas permettent d'élargir et de varier les approches de la culture, selon chaque fois les particularités qu'imposent différents cas nationaux, et d'examiner, en même temps, le rôle dévolu aux supports de cet enseignement, les manuels.

Ana Clara Santos porte dans un premier temps son attention sur les transferts des phénomènes culturels français vers la culture portugaise qui varient entre gallophobie et gallomanie au cours du XVIII ${ }^{e}$ et la première moitié du XIX ${ }^{e}$ siècle, pour ensuite examiner la nouvelle conception idéologique et pédagogique dans l'enseignement de la culture-civilisation. Les instructions officielles et une analyse comparée de certains manuels de français, de la seconde moitié du XIX ${ }^{e}$ siècle, révèlent que le texte littéraire n'est plus exclusivement associé à l'exploitation linguistique mais que, par son caractère et sa thématique moderne, il participe à la connaissance de la civilisation française.

Cette conception de la littérature en tant qu'incarnation de la culture est aussi présente dans l'enseignement du français en Turquie. Arzu Etensel Ildem souligne le rôle de la traduction dans la diffusion de la littérature française mais aussi sa contribution à la modernisation et à l'occidentalisation du pays. L'examen diachronique des programmes d'études des lycées et des départements universitaires en Turquie montre l'importance que l'on attribuait à la culture littéraire mais aussi les carences et les faiblesses d'une pédagogie qui, à l'ère actuelle, semble ne plus pouvoir répondre d'une manière satisfaisante à l'attente des apprenants.

27 Toujours dans le domaine universitaire, Zuzana Malinovská \& Erika Brodňanská rapportent que, dans le cas de la Tchécoslovaquie puis de la Tchéquie et de la Slovaquie, la notion de culture varie au gré des idéologies dominantes qui marquent l'histoire du pays. Avant 1989, c'est la littérature classique, promue par les romanistes, qui reflète la culture et la civilisation françaises. Or, la dichotomie introduite par le marxisme entre culture bourgeoise et culture populaire, faisait passer la culture française comme l'apanage des élites. Pour contrebalancer, l'étude de la civilisation quotidienne offrait une approche plus pragmatique avant que la fin du totalitarisme apporte la modernisation des programmes et des enseignements et un certain équilibre entre culture littéraire et civilisation quotidienne.

L'enseignement de la langue et de la culture françaises s'est aussi investi d'un rôle propagandiste dans le cas des républiques de l'URSS. Dans le cas de la Géorgie, présenté par Catherine Zhorzoliani, on observe comment l'enseignement de la culture dans les classes de français participe à la formation de «l'homme communiste». Choisis à cette fin, les extraits de textes littéraires inclus dans les manuels de lecture de la période 
soviétique, privilégiaient les auteurs "progressistes » et diffusaient une image de la France et de sa littérature conforme aux options idéologiques des pédagogues communistes.

Dans son article, Marcus Reinfried exprime le souhait de voir s'élargir la recherche autour $\mathrm{du} / \mathrm{des}$ modèles de l'enseignement du français langue étrangère qu'ont pu offrir certains pays européens à d'autres aires linguistiques afin de pouvoir dégager ressemblances, influences, divergences... Si l'Allemagne et la Kulturkunde demeurent un modèle pour la Hongrie de l'entre-deux-guerres, c'est le facteur humain, à savoir les pédagogues hongrois auteurs de manuels qui vont jouer un rôle décisif dans la diffusion d'une image positive de la culture française. Comme le démontre Catherine Tamussin, c'est grâce aux choix personnels de pédagogues francophiles que l'image de la culture française reste positive dans un pays qui éprouve une certaine amertume face à la France.

L'approche contrastive des deux cultures présentes dans l'enseignement des langues est une question centrale lorsqu'on aborde les manuels. Mises en contraste, les deux cultures peuvent être considérées à titre d'égalité ou de supériorité, ou encore peuvent servir à accentuer le caractère national. Cette perspective est exploitée dans l'étude de Despina Provata \& Marina Vihou qui analysent une collection de manuels de l'entredeux-guerres spécialement conçus pour les élèves grecs. L'approche de la culture française se fait progressivement, elle reste implicite au début de l'apprentissage pour s'affirmer plus clairement une fois la connaissance de la langue étrangère suffisamment installée chez l'apprenant, et ce sont surtout les manuels complémentaires qui portent la charge culturelle.

31 Toujours dans le monde grec, Phryni Kakoyianni-Doa rappelle les traces toujours palpables du passé français de Chypre et les institutions enseignantes françaises sur l'île pour constater que victimes des outrances du temps, les manuels du XIX ${ }^{e}$ siècle se font rares. Il faudra attendre le $\mathrm{XX}^{\mathrm{e}}$ siècle pour que des ouvrages spécialement conçus et adaptés au contexte local soient réalisés. L'analyse de ces ouvrages montre la variété des thèmes abordés visant à minimiser la distance entre les deux espaces culturels.

Le concept de la culture-civilisation comme composante de l'enseignement d'une langue étrangère ne s'épuise pas bien évidemment avec ces études qui ont révélé - nous semble-t-il - des zones d'influence et d'échange ainsi que certains thèmes récurrents et sur lesquels on devrait peut-être revenir. L'ambition de la SIHFLES est, de toute manière, de poursuivre la réflexion lors d'un prochain colloque.

Le présent numéro de Documents comporte aussi des contributions qui éclairent d'autres aspects de l'histoire du français langue étrangère ou seconde.

Nadéjda Kriajeva se penche sur les rénovations entreprises dans l'enseignement des langues vivantes dans l'école russe après la date charnière de 1871 qui marque la réforme des programmes scolaires. Malgré l'arrivée de la méthode directe et la prolifération de méthodes pour l'enseignement du français, la donne ne change pas et la littérature continue à avoir une place de choix dans l'enseignement du français en Russie et à participer au développement intellectuel des élèves.

La thèse de doctorat de Marjolijn Voogel, dont Marie-Christine Kok Escalle nous livre le compte rendu, examine l'évolution de la place du français dans les Pays-Bas depuis le $\mathrm{XVI}^{\mathrm{e}}$ siècle jusqu'au moment où, sous l'hégémonie culturelle de l'anglais, le français 
s'éclipse progressivement. Visible surtout à partir de 1945, ce changement, se répercute aussi bien dans l'enseignement que dans le monde éditorial.

Le Diccionario de historia de la enseñanza del francés en España que présente J. Fidel Corcuera Manso, s'inscrit dans le domaine de l'historiographie de l'enseignement du français en Espagne. Fruit du travail du laboratoire HIFRES, dirigé par le Professeur Juan García Bascuñana, ce dictionnaire recense manuels et grammaires ainsi que les concepts fondamentaux pour l'histoire du français en Espagne. Couvrant une vaste période allant du XVI ${ }^{e}$ siècle à 1970 , cet ouvrage, disponible en ligne, permet aux spécialistes d'avoir un outil de travail riche et documenté.

Le compte rendu que Henri Besse fait de l'ouvrage de Vladislav Rjéoutski \& Willem Frijhoff intitulé Language Choice in Enlightenment Europe. Education, Sociability, and Governance invite à la lecture pour découvrir l'univers multilingue de l'Europe des XVII ${ }^{\mathrm{e}}$ et XVIII siècles. Entre langues savantes et langues vulgaires c'est le passé social, culturel, religieux et politique de l'Europe qui y est reconstitué.

La thèse de doctorat de Carine Eizlini portant sur Le Bulletin de l'Enseignement de l'AOF, s'inscrit dans le cadre de l'histoire de l'enseignement dans l'école coloniale. Comme le rapporte Gérard Vigner dans son compte rendu, ce genre de périodique spécialisé constitue une source précieuse pour la mise en place des structures éducatives et des initiatives pédagogiques entreprises en milieu colonial.

Qu'il me soit permis, enfin, de remercier la direction éditoriale de Documents, MarieChristine Kok Escalle et Danielle Omer, pour leurs lectures attentives et pour avoir surveillé la réalisation du numéro. 